\section{Textos periodísticos españoles para la historia (1661-2016)}

Virginia Martín Jiménez, María Verónica de Haro de

San Mateo \& Dunia Etura Hernández (2019). Textos periodísticos españoles para la historia (16612016). Madrid: Editorial Cátedra. 352 pp. ISBN: 9788437640167

Desde el siglo XVII, con las primeras formas de periodismo escrito, pasando por la Guerra de la Independencia y el papel crucial de la prensa como formadora de opinión pública, hasta la llegada del diario Sol o El País como representantes del cuarto poder, la historia del periodismo español no puede entenderse sin regresar a los textos de estos y otros diarios que actuaron como testigos del acontecer y como actores implicados en el curso de los acontecimientos.

Casi a modo de una tarea arqueológica, como quien se dispone a desempolvar las huellas y vestigios del pasado, Textos periodísticos españoles para la historia (2019), realizado de

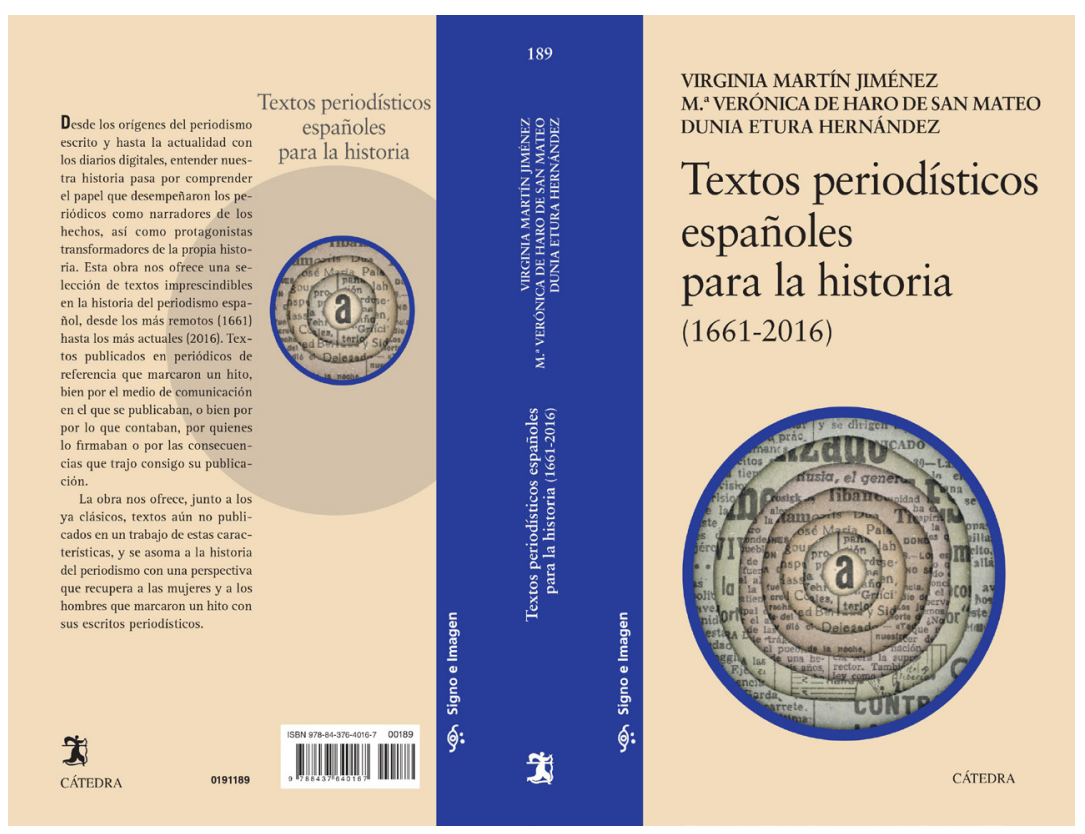

manera conjunta por las profesoras de universidad, Virginia Martín Jiménez, $M^{a}$ Verónica de Haro de San Mateo y Dunia Etura Hernández, es resultado de la difícil tarea de revisar ese pasado periodístico, que, aunque fascinante, no deja de albergar ciertos huecos como los que viene a llenar su propuesta.

Si bien algunos manuales de referencia ponen sobre la pista artículos esenciales que marcaron un antes y un después en el periodismo, bien por la persona que los firmaba o por el momento de su publicación, las páginas de este trabajo ofrecen un aporte extraordinario que ordena y referencia ese sin fin de piezas dentro de un mar de artículos complejo y confuso y, además, añade una perspectiva absolutamente necesaria: la que reivindica las aportaciones femeninas. Ciertamente, la cuidada labor retrospectiva que realizan las autoras, comprobable en el índice de las páginas finales y la presentación de los 75 textos periodísticos incluidos en el libro, quedaría empobrecida si no pusiese el foco sobre las firmas femeninas, muchas veces silenciadas, otras tantas reprimidas, y que requerían de una revisión crítica como la que se presenta para recibir con justeza el papel que se merecen las mujeres en el periodismo.

Esta doble ambición, la de señalar los aportes más relevantes del perio- 
dismo español y la de recuperar las figuras femeninas frecuentemente orilladas por la historiografía, conforman una brillante antología, que, más allá de la mera actualización de títulos, nombres y periódicos, adopta la forma de un auténtico manual nutrido de la experiencia docente de las autoras para ofrecer una utilísima herramienta didáctica. De acuerdo a su estructura, el libro presenta un carácter cronológico. Tras unas primeras páginas de introducción, el primer capítulo corresponde al siglo XVII. Los seis siguientes se zambullen en el periodismo del siglo XVIII y los quince que le suceden pertenecen al siglo XIX. La centuria del XX es la que más capítulos abarca, desde el número 23, dedicado a Emilia Pardo Bazán y su artículo Los pazos de Ulloa (1886), hasta el 69, que cierra con Joaquín Vidal y su crónica taurina. El broche lo ponen seis capítulos finales que se refieren a la revolución tecnológica del siglo presente, con la digitalización y las nuevas formas narrativas.

Sumando aportaciones inéditas, este libro responde a su vocación formativa e introduce las publicaciones con unas líneas en las que se explica su relevancia histórica, así como la importancia del hombre o mujer detrás de su creación o el medio que las difundía. Además, para facilitar la lectura, la grafía de las piezas más antiguas ha sido actualizada al estilo de la redacción actual, lo que permite su total compresión y sortear los obstá- culos propios de acceder a hemerotecas tan vetustas.

Pese a que, como reza su prólogo, "no son todos los que están", el cometido bajo el que nace este trabajo se ve cumplido con creces y hace honor a su título, pues sus párrafos desgranan de manera inteligente esos "textos periodísticos para la historia" que, al mismo tiempo, son los textos de la historia nacional. Gracias a esta selección amplísima, que comienza con una Gazeta impresa en Sevilla en 1661 y acaba asomándose al siglo XXI, el lector puede echar la vista atrás y adentrarse en las múltiples noticias, opiniones o editoriales a los que acompañaron nombres tan significativos como los de Mariano Nipho, un adelantado a su tiempo y que fue consciente del papel clave de la prensa en la sociedad; Concepción Arenal, en la línea de las sufragistas femeninas decimonónicas; o Manuel Chaves Nogales, periodista de dimensión internacional que llegó a colaborar con la BBC inglesa.

Las aportaciones de estos últimos, junto a otras procedentes de figuras pertenecientes al ámbito de la filosofía, como José Ortega y Gasset, o al de la literatura, como Leopoldo Alas, Clarín, permiten ya no solo la recopilación de materiales imprescindibles, desde el punto de vista patrimonial, sino que también hacen posible la revisión de muchos pensadores, políticos e intelectuales, influenciados por las corrientes y tendencias de cada época (de ahí que la obra no se reduzca exclusivamente al ámbito español). Grandes periodistas a lo largo de la historia de España han hecho de la prensa una forma de explicación imprescindible para conocer y comprender con claridad lo que sucedía, como así lo demuestra esta obra, inteligente y de notoria profundidad. Reivindicado sus nombres, también los de las periodistas -que fueron muchas-. Textos periodísticos españoles para la historia, en definitiva, constituye un recopilatorio de enorme valor que es tanto lectura para el disfrute personal, como manual para profesores e investigadores.

\section{Jacobo Herrero Izquierdo}

Universidad de Valladolid, España

jacobo.herrerodalumnos.uva.es 